\title{
STUDIES ON THE PHYSICAL DEPENDENCE POTENTIAL OF ANALGESICS
}

\author{
Tadashi MURANO, Hiromi SENDA, Hiroyuki YAMAMOTO \\ and Ichiro YANO \\ Department of Pharmacology, Wakayama Medical College, Wahayama 640. Japan
}

Accepted January 6, 1978

\begin{abstract}
Absiract-Influence of morphine on the line structure of mitochondria in the cell of zona fasciculata of adrenal cortex in mice treated chronically with morphine pellets was studicd using the electron microscope. The transformation of mitochondrial structure was observed 12 hours after morphine pellct implantation and the degree of transformation reached a maximum at 48 hours. These changes, however, disappeared within 4 days. On the 4 th day after implantation, removal of the pellet or levallorphan challenge resulted in alteration of the mitochondria with evidence of withdrawal syndrome. Reinjection of morphine to the mice immediately after removal of the pellst, however, prevented the appearance of such mitochondrial transformation. Chlorpromazine or sodium pentobarbital did not affect on the transformation of mitochondria.
\end{abstract}

We have already reported that abrupt withdrawal of morphine or challenge of either Icvallorphan or naloxone in morphine dependent rats resulted in a characteristic transformation of intramitochondrial structure in the adrenal cortex (1-4). The time course of appearance of these changes coincides with that of marked loss in body weight after withdrawal, the latter considered to be onc of the best indicators of physical dependence on morphine (5-7). When morphine was readministered, normal structures of the mitochondria were readily restored.

Fron these results, we suggested that there is a close relationship between these changes and the physical dependenec potential and that the transformation of mitochondria may be one of the best indices of physical dependence in rats.

Way et al (8) used the naloxone induced jumping behavior to quantify the degree of physical dependence in morphinized mice. They reported an inverse relationship between the degree of dependence and the amount of naloxone required to induce the jumping responses. Since then, this method has been widely used in many laboratories (7-13). Should the appearance of mitochondrial alteration observed in morphine dependent rats be evident in morphine pellet implanted mice in which it has been confirmed that acute dependence on morphine had developed, it is conceivable that a close relationship between the transformation of mitochondria and the dependence potential would prove to be a phenomena common to all rodents and the mitochondrial structure would be one of the best indicators of the degree of physical dependence potential.

We carried out experiments to determine whether or not such transformation of mitochondria is indeed produced in morphine dependent mice after abrupt withdrawal of the drug. 


\section{MATERIALS AND METHODS}

Male ICR mice from CLEA Japan INC. (Tokyo) weighing 27 to $30 \mathrm{~g}$ were housed in our laboratory for at least 1 weck prior to experimentation. Food and water were provided ad libitum.

Morphine pellets used in this experiment were prepared by the method of Way et al (8). Such consisted of morphine base, $75 \mathrm{mg}$; microcrystalline cellulose, $75 \mathrm{mg}$; fumed silicon dioxide, $0.75 \mathrm{mg}$; and calcium stcaratc, $1.5 \mathrm{mg}$. Placebo pellets consisted of $75 \mathrm{mg}$ of lactose instead of the morphine base. The $7 \mathrm{~mm}$ pellets were implanted s.e. in the dorsal region of mice under ether ancsthesia.

To confirm the development of tolcrance to and physical dependence on morphine in the pellet implanted mice, the following preliminary experiments were performed.

The pellets were removed at various days after implantation and the absorption rate from the morphine pellets was determined by quantifying the amount of drug remaining at the implantation site (14). Twenty $\mathrm{mg} / \mathrm{kg}$ of morphine was then injected 6 hours after removal of the morphine pellet and the grade of tolerance was assessed.

The degree of tolerance was measured using an clcctro-shock method (15) by plotting the mcan analgesic response time against the time after injection of morphine on section paper and determined the area under the response curve.

The degree of physical dependence on morphine was assessed by the decrease in body weight and the withdrawal jumping behavior after abrupt withdrawal of morphine or challenge with $10 \mathrm{mg} / \mathrm{kg}$ of levallorphan.

In these experiments, we confirmed the following: 1) About $22 \mathrm{mg} / \mathrm{kg}$ of morphine was absorbed from the pellet during the initial 4 days and a particularly large amount was absorbed during the 1 st and 2 nd days. 2) The development of tolerance after morphine pellet implantation was discernible within $24 \mathrm{hr}$, but progressively increased with increasing time, reaching the maximal state on the 3rd or 4th days. 3) Marked loss of body weight and characteristic withdrawal jumping behavior were induced by abrupt withdrawal of morphine or the levallorphan challenge. In the abrupt withdrawal group, maximal effects occurred at $10 \mathrm{hr}$ (loss of body weight) and $6 \mathrm{hr}$ (jumping), respectively, but in the mice in the levallorphan challenged group maximal cffects were seen at 2 hr (loss of body weight) and 15 min (jumping), respectively.

These results are good agreement with those of Maggiolo and Huidobro (16), Huidobro (17) and Way et al (8), and indicate that the development of tolerance to and dependence on morphine were thoroughly induced in these mice. Electron microscopic studies were then done using those mice.

The animals were anesthetized with pentobarbital and prefixed with perfusion of formaldehyde $(2 \%)$ and glutaraldehyde $(2.5 \%)$ solution adjusted to $\mathrm{pH} 7.4$ with $0.1 \mathrm{M}$ of Sörensen phosphate buffer which was given through left cardiac ventricle.

The adrenals were removed immediately after perfusion and postfixed with $1 \%$ buffered osmium tetraoxide for $3 \mathrm{hr}$ at $4 \mathrm{C}$. Dehydration was carried out using a graded series of chillcd ethanol. The blocks were then embedded in Epon 812 and sections were cut with 
glass knives in a Porter Blum MT-1 and Reichert Om- $\mathrm{U}_{2}$ ultramicrotome after polymerization in an incubator. To identify the outer region of the zona fasciculata, semi-thin sections $(1 / 1)$ were cut from the Epon block, stained with toluidine blue and viewed under light microscope. The ultrathin sections were stained with uranylacelate-lead citrate, and examined under a JEM-100L electron microscope. Ten photographs at relatively low magnification from various regions of outer zone of zona fasciculata were taken and the results examined.

\section{RESULTS}

Fine structure of adrenal correx in normal mice

Zona glomerulosid forms the outermost layer of the adrenal cortex and consists of 3-4 cell layers. It is localed between the capsule which is composed of a few fibrous cells with many collagenous fibers and the zona fasciculata. These layers have irregular diamond shaped or cylindrical cells which have an irregular ovoid nucleus, elliptical mitochondria with a conb-like inner structure, lipid droplets and a relatively clear cytoplasm. These cell layers gradually shifted to the zona fasciculata through 1 or 2 layers of the intermediate zone.

As shown in Fig, 1, in the cells of zona fasciculata of normal mice, there are many dark cells which are compactly filled with mitochondria, smooth endoplasmic reticulum and lipid droplets. Characteristic mitochondria are nearly globular in shape with a diameter of about $0.5 \%$, but their inner structure varies from cell to cell, i.e., vesicular, tubular, tubulovesicular or mitochondrial ghost which decrease in electron density of the matrix and have the appearance of empty mitochondria. Therefore, the inner structure of mitochondria in zona fasciculata of normal mice is considerably different from that of normal rats (1). Size of the mouse mitochondria is slightly smaller and the inner structure is more irregular than that seen in rats. This tendency is more evident in the inner zone of zonal fasciculata

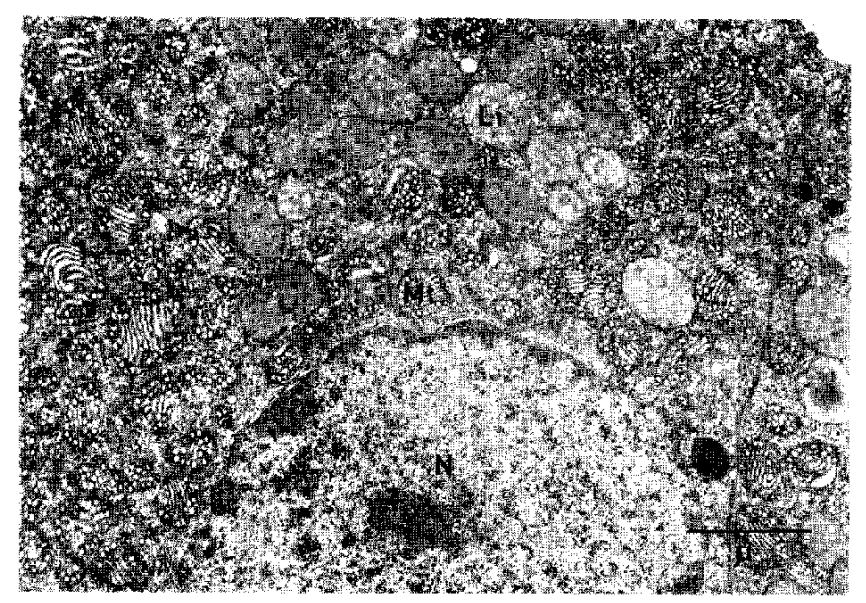

FIG. 1. Electron micrograph of adrenocortical cells of zona fasciculata in control mouse. Mt: mitochondria. Ly: lysosome, Li: lipid droplet. N: nucleus 
or in zona reticularis. About $80-85 \%$ of mitochondria in zona lasciculata revealed a vesicular or tubulo-vesicular structure with high electron density, and the remaining $15-20 \%$ of mitochondria showed a tubular or empty type with low electron density, in other wards. transformed mitochondria as scen in dependent rats were also observed even in normal mice.

\section{Effects of the morphine pellet implantation}

Twelve hr after implantation of morphine pellets, the cells of zona fasciculata became relatively clear with an increasing endoplasmic reticulum. Mitochondria of these cells began to swell and at the same time intramitochondrial structure became tubular or had at concentric lamellar structure with an empty area in their matrix. These altered mitochondria nearly doubled in the number during this time and then gradually increased. A

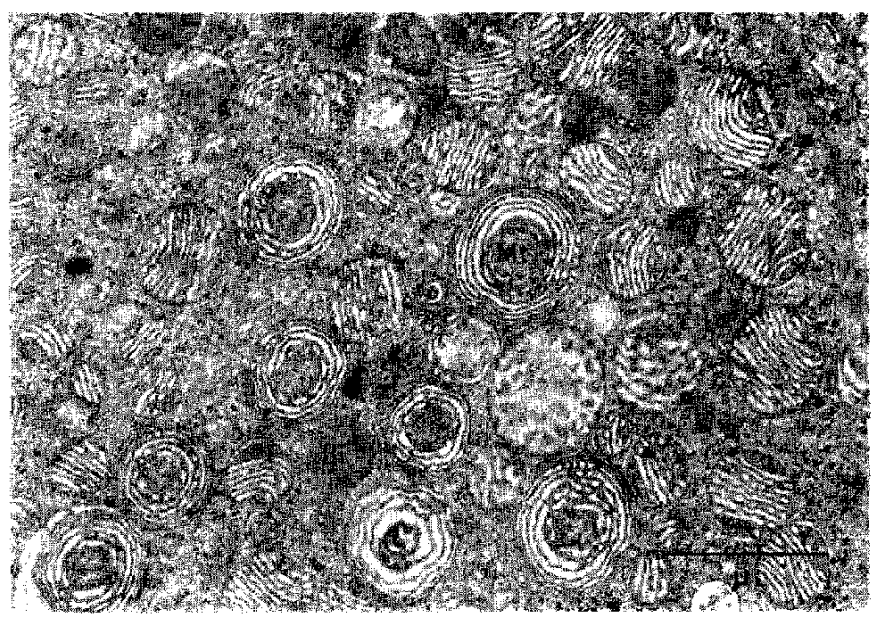

Fici. 2. Mitochondria of zona fasciculata of adrenal cortex in mouse implanted morphine pellet for 24 hours

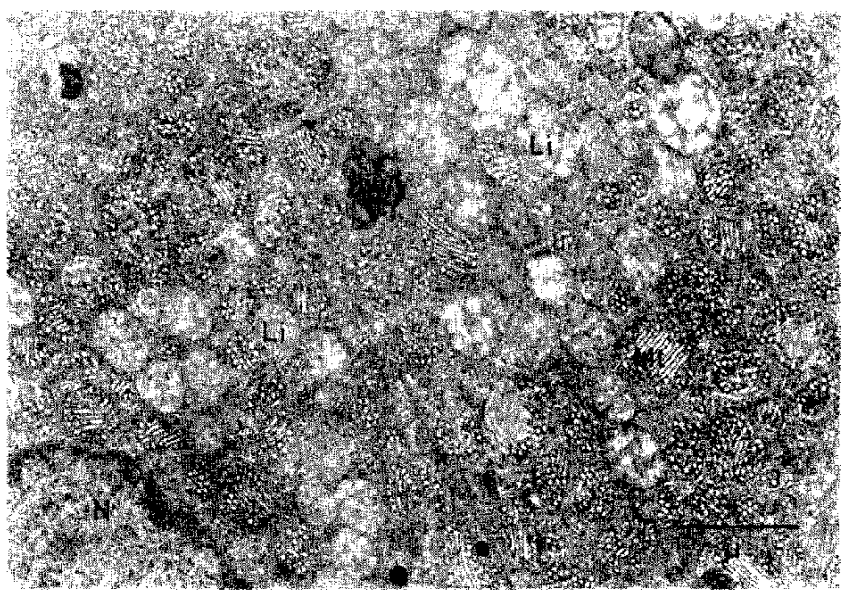

Fro. 3. Mitochondria of rona fasciculata of adrenal cortex in mousc implanted mopphine pellet for 96 hours. 


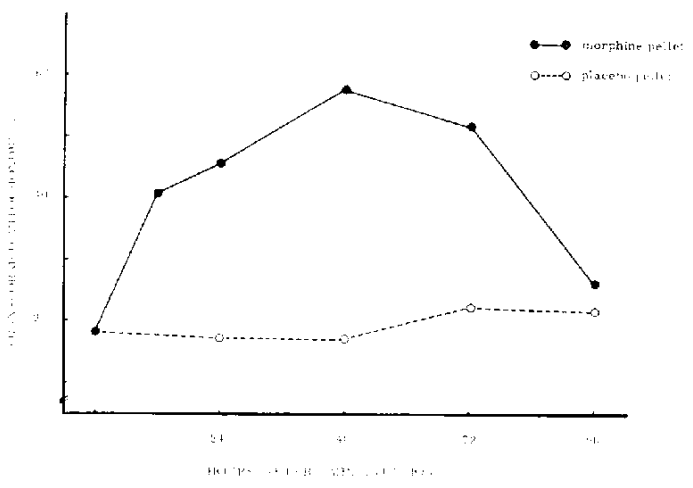

Fig. 4. Transformation of mitochondrial structure in zona fasciculata of adrenal cortex in mice after implantation of morphine pellet or placebo pellet.

maximum state was reached (about $60 \%$ ) at 48 hr as shown in Fig. 2. Three days after pellet implantation, these altered mitochondria diminished rapidly despite the continuance of pellet implantation and a normat state was reverted to within 4 days (Fig. 3).

We also investigated the influence of placebo pellet in normal mice, and no considerable changes were found. These findings indicate that the opcrative injury with the pellet implantation did not affect the transformation of mitochondria (Fig. 4).

\section{Etfects of the morphine pellet removal or lexallorphan chalknge}

Four days after morphine pellet implantation when morphological changes disappeared and a normal appearance was seen, pellets were removed and the intramitochondrial structure was investigated at various intervals. Three hr after removal of the pellet, the mitochondria began to swell and inner membrane of some mitochondria showcd a tubular or lamellar structure. These changed mitochondria gradually increased but mitochondrial ghosts were comparatively few at this time. Six hr later, such diminished temporarily, but gradially increased thereafter and reached a maximum state at $18 \mathrm{hr}$ after removal of the pellet (Fig. 5).

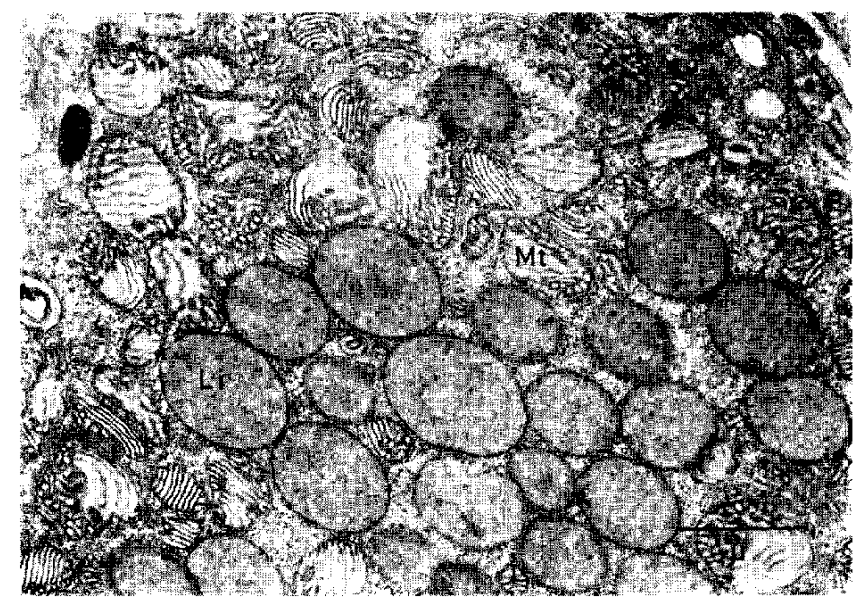

Fici. 5. Fighteen hours after removal of morphine pellet implanted for 96 hours. 
One of the characteristic features of these mitochondria was a decrease in electron density of the mitochondrial matrix and an increase in the number of cmpty mitochondria. These mitochondrial ghosts or empty mitochondria formed the majority in altered mitochondria. Such began to decrease after $24 \mathrm{hr}$ and normal structures were reverted to within $72 \mathrm{hr}$.

Since the tubular or empty mitochondria were transiently observed in normal mice $3 \mathrm{hr}$ after removal of the placebo pellet, the appearance of altered mitochondria seen after removal of morphine pellet apparently increased within $18 \mathrm{hr}$ and gradually decreased thereafter.

In the next experiment, when $10 \mathrm{mg} / \mathrm{kg}$ of levallorphan was administered without removal of the pellet from mice in which the morphine pellet had been implanted 4 days previously, no significant changes had occurred within $3 \mathrm{hr}$, but 6-12 hr later, similar changes as seen in the abrupt withdrawal mice were evident (Fig. 6, 7). At this time, empty mito-

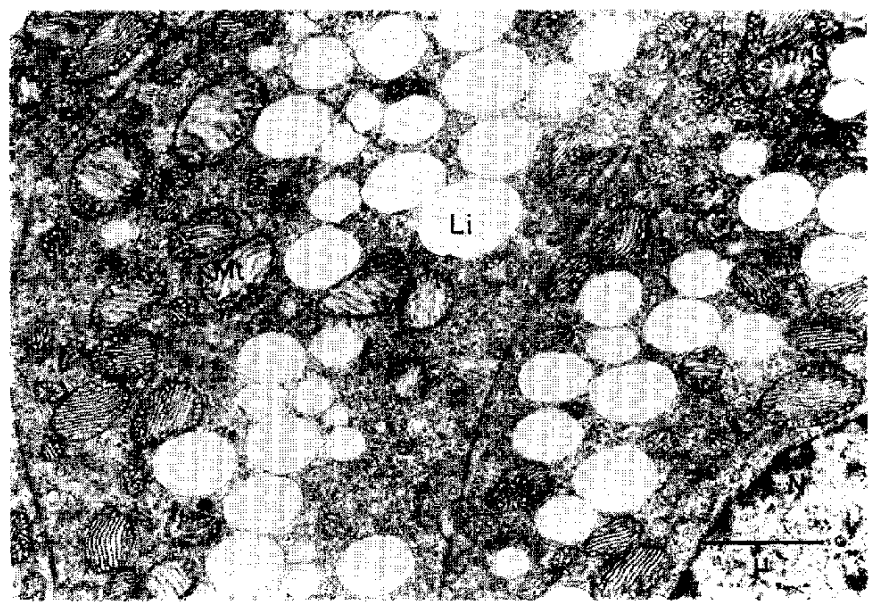

Fig. 6. Transformation of mitochondria of adrenocortical cells in the morphine dependent mouse. Ten hours after levaliorphan challenge.

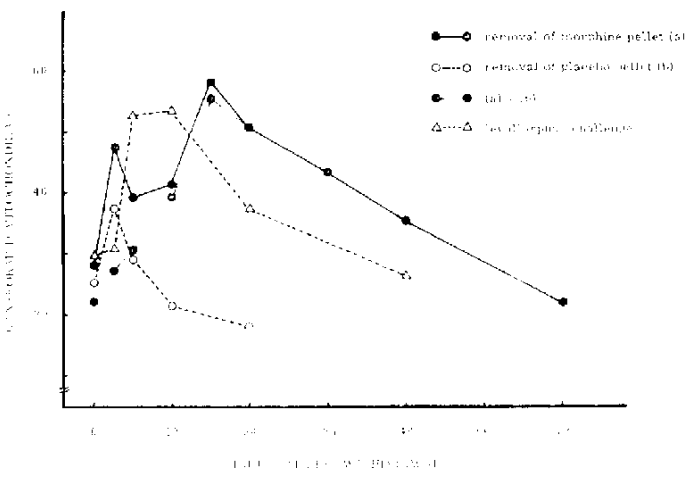

FIG. 7. Transformation of milochondrial structures in zona fasciculata of adrenal cortex in mice after removal of morphine pellet or levallorphan challenge (10 mg $\mathrm{kg}$, s.c.) to mice with a morphine or placebo pellet implanted for 96 hours. 
chondria were also noted to be in the majority in the altered mitochondria. The appearance of these changed mitochondria induced by levallorphan challenge occurred earlier than that caused by abrupt withdrawal and disappeared within $48 \mathrm{hr}$. A slight increase of smooth endoplasmic reticulum accompanied by the transformation of mitochondria was observed, but there were no significant changes in nucleus, Golgi apparatus and lipid droplets.

\section{Effects of readministration of morphine}

When $80 \mathrm{mg} / \mathrm{kg}$ s.c. of morphine was readministered to the mice in which the morphine pellet had been removed 6 hr previously, not only was the appearance of altered mitochondria inhibited, but a normal appearance was reverted to within 4-6 hr. Two hr after readministration, electron density of mitochondrial matrix increased significantly and at the same time vesicular or tubulo-vesicular structure began to increase and smooth endoplasmic reticulum became more evident (Fig. 8). Eight hr after readministration, however, the number of altered mitochondria showed a slight increase (Fig. 9).

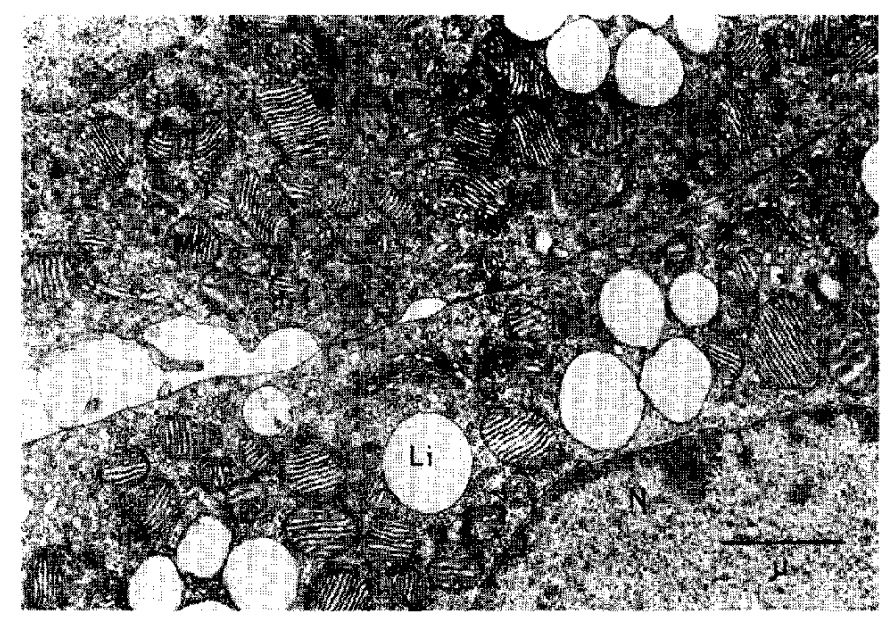

Fig. 8. Two hours after administration of morphine at 6 hours after removal of morphine pellet.

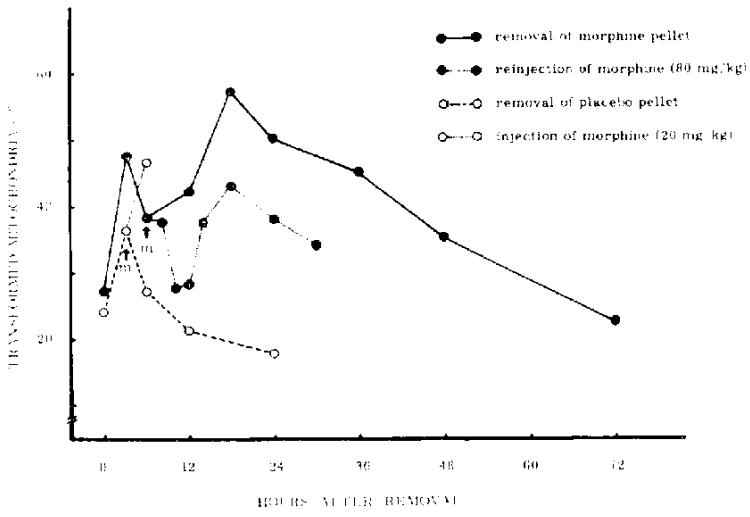

Fig. 9. Effect of morphine administration on the transformation of mitochondria followed by removal of morphine pellet or placebo pellet. 
As descrived above, a slight and transient change of mitochondrial structure occurred after removal of placebo pellet. At this lime, changed mitochondria increased even more with administration of $20 \mathrm{mg} / \mathrm{kg}$ s.c. of morphine.

Fffects of various agents on the transformation of mitochombia

Four days after implantation of the morphine pellet, mice were given $20 \mathrm{mg} / \mathrm{kg}$ of chlorpromazine s.c. or $30 \mathrm{mg} / \mathrm{kg}$ of sodium pentobarbital i.p. These mice were then challenged with $10 \mathrm{mg} / \mathrm{kg}$ of levallorphan. Six hr later, the mitochondrial inner structure was investigated.

After injection of chlorpromazine or sodium pentobarbital, percentages of the altered mitochondria were 51.7 and 54.1, respectively. These agents alone apparently had no effect on the mitochondrial structure, therefore probably played no role in the transformation of mitochondria.

\section{DISCUSSION}

Morphine pellet implantation was first described by Maggiolo and Huidobro (16) and later, Way et al (8) improved this method. These authors reporied that tolcrance to and physical dependence on morphine rapidly developed by implantation of morphine pellet and that such reached a maximum state at 24 days. Our data in the present experiments are in good agreement.

We previously reported that there is a close relationship between the dependence potential of narcotic analgesic drugs and the transformation of mitochondria of zona fasciculata in rats and that the latter should be one of the best indices of physical dependence on morphine (1-4). This assumption was confirmed also in mice, in the present experiments (Fig. 10).

It is well known that the appearance of transformed mitcchondria exhibits a lowering of corticosteroid biosynthesis $(2,18-22)$. This decrease may be induced during the withdrawal period in morphine dependent mice as well as rats. If such is indeed correct, then why is the transformation of mitochondria, similar to that observed during the period of

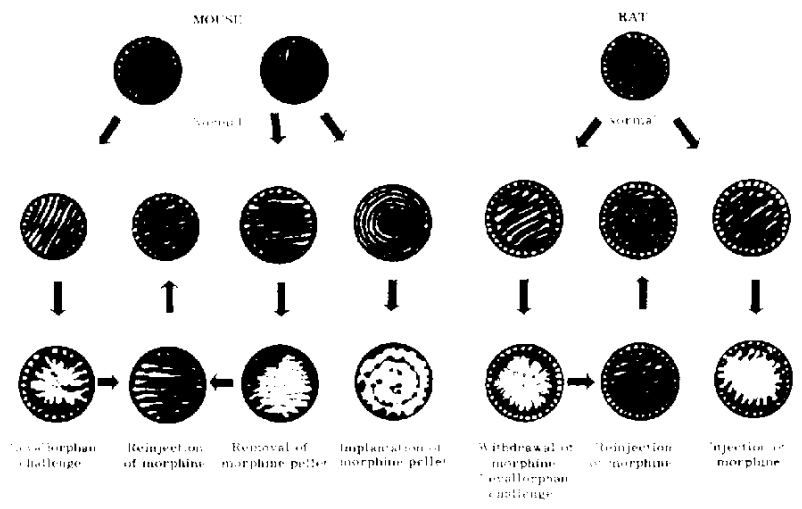

Fic. 10. Comparison of the schematic representation of ultrastructural changes of zona fasciculata mitochondria of mouse and rat adrenal cortex under various treatments. 
withdrawal, induced in the early stage of pellet implantation and thereafter disappears? What possible explanation is there for the discrepancy between the findings that a single dose of morphine stimulates the hypophyseo-adrenocortical axis (23-25) and the results of our present experiments?

Yano et al. (1-4) found that the transformation of mitochondria seen in withdrawal period was induced at $6-12 \mathrm{hr}$ after a single injection of morphine, but they did not give a full explanation for this phenonenon.

Yamanoto et al. (26-28) gave a continuous infusion of morphine to rats in order to elucidate this contradictory phenonenon. They reported that the tolerance to and dependence on morphine rapidly developed in a short period when this method was used, but that the time course of the disappearance of tolerance did not always coincide with that of dependence. They also suggested that the alterations of mitochondria may thus be the result of differences in duration of tolerance and physical dependence.

Thus, the transformation of mitochondria observed 1-2 days after implantation of morphine pellet in mice may be due to over development of dependence rather than that of tolerance and the following disappearance of altered mitochondria may be the result of a development of tolerance which parallels that of dependence.

\section{REFERENCES}

1) Yano, I., Nishino, H., Yamamoto, H. and Murano, T.: Studies on the physical dependence liability of analgesics. 1st report: Electron microscopic studies on the ultrastructural transformation of mitochondria in the cells of zona fasciculata of the adrenal cortex in morphine addicted rats. Japan. J. Pharmacol. 23, 201-215 (1973)

2) Yamamoto, H., Mikita, S., Yano, I., Masuda, Y. And Murano, T.: Studies on the physical dependence liability of analgesics. 2nd report; Relationship between transformation of intramitochondrial struetures in adrenocortical cells and corticosterone biosynthesis in morphine addicted rats. Japan. J. Pharmacol. 23, 217-225 (1973)

3) Yano, I., Nishino, H., Masuda, Y., Yamamoto, H. and Murano, T.: Studies on the physical dependence liability of analgesics. 3 rd report: Electron microscopic study on intramitochondial structure of zona fasciculata cells in adrenal cortex in a new analgesic, CG-315 chronically administered rats. Japan. J. Pharmacol, 23, 227-231 (1973)

4) Yano, I., Masuda, Y., Nishino, H., Yamamoto, H. and Murano, T.: Studies on the physical dependence liability of analgesics. 4th report: Electron microscopic study on intramitochondrial structure of zona fasciculata cells in adrenal cortex in codeine addicted rats. Japan. J. Pharmacol. 23, 313-319 (1973)

5) Yoshmoto, H.: Studies on chronic poisoning of morphine in rats, with special reference to its abstinence phenonenon and effects on adrenal gland. J. Med. Soc. Toho 12, 180$192(1965)$

6) Akfra, T. AND BRody, T.M.: The addiction cycle to narcotics in the rat and its relation to catecholamine. Biochem. Pharmacol. 17, 675-688 (1968)

7) Yamamoto, H., Hayano, T., Masuda, Y. and Murano, T.: Studies on the physical dependence of a new central analgesics; 1-(m-methoxyphenyl)-2-dimethylaminomethyl cyclohexanol (1) HCl (CG-315). Japan. J. Pharmacol. 22, 715-720 (1972)

8) WAY, E.L., LOH, H.H. AND SHEN, F.H.: Simultaneous quantitative assessment of morphine tolerance and physical dependence. J. Pharmacol. exp. Ther. 167, 1-8 (1969)

9) Cheney, D.L. and Goldsiein, A.: Tolerance to opioid narcotics: Time course and reversibility of physical dependence in mice. Nature 232, 477-478 (1971)

10) Marshall, I. AND Weinstock, M.: Quantitative method for assessing one symptom of the withdrawal syndrome in mice after chronic morphine administration. Nature 234, 
223-224 (1971)

11) Saelens, J.K., Granat, F.R. and Sawyer, W.K.: The mouse jumping test: a simple screenig method to estimate the physical dependence capacity of analgesics. Archs int. Pharmacodyn. Thér. 190, 213-218 (1971)

12) Smits, S.E.: Quantitation of physical dependence in mice by naloxone-precipitated jumping after a single dose of morphine. Res. Commun. Chem. Path. Pharmacol. 10, 651-661 (1975)

13) YANO, I. AND TAKEMORI, A.E.: Inhibition by naloxone of tolerance and dependence in mice treated acutely and chronically with morphine. Res. Commun. Chem. Path. Pharmacol. 16, 721-734 (1977)

14) Pharmacopoeia Japonica (Editio Nona).: Morphini Hydrochloridum, Edited by NAG.3\$1, Y., p. 223-226, Hirokawa Publishing Co. Ltd. Tokyo, Japan (1976)

15) Grewal, R.S.: A method for testing analgesics in mice. Brit. J. Pharmacol. 7, 433-437 (1952)

16) Maggrolo, C. And Hudobro, F.: Administration of pellets of morphine to mice; abstinence syndrome. Acta physiol. latinoam. 11, 70-78 (1961)

17) Hutdorro, F.: Some relations between tolerance and physical dependence to morphine in mice. Europ. J. Pharmacol. 15, 79-84 (1971)

18) Sabatini, D.D., De Roblertrs E.D.P. And Bleichmar, H.B.: Submicroscopic study of the pituitary action on the adrenocortcx of the rat. Endocrinology 70, 390-406 (1962)

19) Nishikawa, M., Murone, I. and Sato, T.: Electron microscopic investigations of the adrenal cortex. Endocrinology 72, 197-209 (1963)

20) KAHRI, A.I. : Effects of actinomycin D and puromycin on the ACTH-induced ultrastructural transformation of mitochondria of cortical cells of rat adrenal in tissue culture. J. cell Biol. 36, 181-195 (1968)

21) SEkTYAMA, S. AND YAGO, N.: A study on the correlation between function and ultrastructure in the rat adrenal cortex. Acta Pathol. Japon. 22, 77-98 (1972)

22) KAHRI, A.I.: Inhibition of ACTH-induced differentiation of cortical cells and their mitochondria by corticosterone in tissue culture of fetal rat adrenals. Ant. Rec. 176. 253$272(1973)$

23) Epsteiv, S., Burdetre, H. AND MUnsoy, P.L.: Effect of nalorphine on inhibition of ACTH release by morphine in the rat. Fedn Proc. 16, 294 (1957)

24) TANABE, T. AND CAFRUNy, E.J.: Adrenal hypertrophy in rats treated chronically with morphine. J. Pharmacol. exp. Ther. 122, 148-153 (1958)

25) Nikonilbvic, O. AND Maickel, R.P.: Some effects of morphine on pituitary-adrenocontical function in the rat. Biochem. Pharmacol. 16, 2137-2142 (1967)

26) Yamavoto, H. Yano, I. and Murano, T.: Acute tolerance to morphine in rats. Japan. $J$. Pharmacol. 22, Suppl. 91P (1972)

27) Yamamoto, H, Yano, I. And Murano, T.: Acute morphine tolerance and physical dependence in rats. Japan. J. Pharmacol. 23, Suppl. 57P (1973)

28) Yamamoto, H., Kuchit, M., Yano, I. and Murano, T.: Acute morphine tolerance and physical dependence in rats; Development of physical dependence and disappearance of tolerance and physical dependence. Japan. I. Pharmacol. 24, Suppl. 122P (1974) 